\title{
GERMINAÇÃO E CRESCIMENTO DE MUDAS DE PITANGUEIRA (Eugenia uniflora L.) SOB CONDIÇÕES DE SOMBREAMENTO'
}

\author{
SILVANA DE PAULA QUINTÃO SCALON 2; HOMERO SCALON FILHO; \\ MARILÚCIA ROSSI RIGONI ${ }^{4}$, FERNANDA VERALDO ${ }^{4}$
}

\begin{abstract}
RESUMO - Os objetivos deste trabalho foram avaliar a capacidade germinativa das sementes de pitanga e o crescimento das mudas sob condições de sombreamento. O experimento foi conduzido na Área de Pesquisa Experimental da UNIGRAN - Dourados-MS. O teste de germinação foi realizado com 300 sementes, sendo avaliados a porcentagem de germinação e o índice de velocidade de emergência. Aos três meses após a emergência, o experimento de crescimento das mudas foi instalado em um delineamento de blocos casualizados, com três tratamentos (sombrite $50 \%$ e $70 \%$ de luz e a pleno sol), em 4 repetições de 15 mudas por tratamento. Quando as mudas apresentavam 4; 5; 6 e 7 meses de idade, foram avaliados a altura e o diâmetro de caule, e ao final do ensaio, foram avaliados o peso seco total das mudas $(\mathrm{g})$, a área foliar $\left(\mathrm{dm}^{2}\right)$, a razão de peso foliar - RPF $(\mathrm{g} / \mathrm{g})$ e o peso específico de folhas - PEF $\left(\mathrm{g} / \mathrm{dm}^{2}\right)$. A pitangueira é uma espécie de fácil propagação por sementes, apresentando $65,7 \%$ de germinação e índice de velocidade de emergência de 3,34, sendo que as sementes iniciaram o processo de germinação aos 23 dias após a semeadura. As mudas cresceram melhor sob condição de luz plena, onde apresentaram maior altura, diâmetro de caule, peso seco e área foliar.
\end{abstract}

Termos para indexação: germinação, sombrite, pitanga

\section{GERMINATION AND GROWTH OF Eugenia uniflora L. SEEDLINGS UNDER SHADE CONDITIONS}

\begin{abstract}
The objectives of this work were to evaluate germination capacity of Eugenia uniflora L. seeds and the growth of seedlings under shade conditions. The experiment was carried out at Experimental Research Area of the UNIGRAN - Dourados, MS. Germination test was done with 300 seeds and germination percentage and emergence speed index were evaluated. At the third month after emergence, the seedling growth experiment was carried out in a randomized block design with three treatment $(50 \%$ and $70 \%$ of sunlight and at full sunlight) with four replications of 15 seedlings each treatment. When seedlings presented 4, 5, 6 and 7 months of age, height and stem diameter were evaluated and at the final of the experiment, total dried weight of seedlings $(\mathrm{g})$, leaf $\operatorname{area}\left(\mathrm{dm}^{2}\right)$, leaf weight rate - RPF $(\mathrm{g} / \mathrm{g})$ and leaf specific weight $-\mathrm{PEF}\left(\mathrm{g} / \mathrm{dm}^{2}\right)$. Eugenia uniflora $\mathrm{L}$. is specie of easy propagation by seeds presenting $65,7 \%$ of germination and emergence speed index of 3.34, and seeds began their germination process 23 days after sowing. Seedlings growth better under full sunlight conditions, where they showed biggest height, stem diameter, dried weight and leaf area.
\end{abstract}

Index terms: germination, shade, pitanga .

\section{INTRODUÇÃO}

As árvores produzem valiosos produtos como madeira para os mais diversos fins, frutos comestíveis, forragens, resinas ou gomas, produtos químicos, medicamentos, néctares, polens e lenha, dentre outros (Silva et al., 1997). As conseqüências da grande devastação na cobertura vegetal do País tem sido a eliminação direta de espécies vegetais, a redução da oferta de alimento e o abrigo para a fauna silvestre, a exposição das bordas do fragmento à irradiação solar direta, e o favorecimento ao estabelecimento de espécies invasoras (Souza e Silva, 1994).

A vegetação do cerrado apresenta uma grande riqueza florística, e, segundo Batalha et al. (1997), vários pesquisadores têm feito levantamentos dessas espécies. Entretanto, ainda são poucos os estudos sobre a propagação e desenvolvimento das mudas das espécies nativas dessa região. Grande parte do esforço da silvicultura visando a maximizar a obtenção de produtos florestais como madeira, látex, frutos e resinas baseia- se no cultivo de espécies mais adaptadas a condições de luz, temperatura e umidade entre outros fatores da região do cerrado (Martins, 2000).

Embora geralmente as sementes de cerrado germinem sem dificuldade, existem problemas de estabelecimento no habitat. As espécies do gênero Eugenia parecem não ter problemas de germinação, uma vez que elas caem no início das chuvas; entretanto, a sobrevivência das mudas pode ser afetada (Rizzini, 1971).

A pitangueira (Eugenia uniflora - Myrtaceae) é uma árvore frutífera medindo cerca de $6-12 \mathrm{~m}$ de altura, podendo ser utilizada no paisagismo ou cultivada em pomares domésticos. A madeira é empregada na confecção de cabos de ferramentas e outros instrumentos agrícolas. Floresce entre agosto e novembro e os frutos amadurecem entre outubro e janeiro. (Lorenzi, 1998). $\mathrm{O}$ fruto do tipo drupa, contendo de 1 a 2 sementes, apresenta entre outros nutrientes, a Vitamina C. A pitanga pode ser utilizada para diminuir a pressão arterial, combater azia, bronquite, cólicas

1 (Trabalho 240/2000). Recebido: 30/10/2000. Aceito para publicação: 04/10/2000.

2 Bióloga Professora da UNIGRAN silvana@unigran;

3 Agrônomo Professor da UNIGRAN;

4 Acadêmicos do Curso de Ciências Biológicas da UNIGRAN, Rua Balbina de Matos 2121, CEP: 79824-900, Dourados-MS. 
e doenças do estômago (Korbes, 1995), o chá das folhas é antireumático, antidisentérico, febrífugo e utilizado contra diabetes. Os agricultores utilizam a pitanga também pela versatilidade dos frutos que, além de serem utilizados na cosmetologia, fornecem geléias, doces, refrescos, sorvetes, licores e vinhos de qualidade apreciável. A pitangueira é recomendada também para reflorestamentos heterogêneos destinados à recomposição de áreas degradadas de preservação permanente, visando a proporcionar alimento a avifauna.

A luz que atravessa o dossel da floresta, sofre mudanças consideráveis quanto à sua intensidade, duração e qualidade. Em geral, os diferentes graus de luminosidade causam mudanças morfológicas e fisiológicas na planta, e o grau de adaptação é ditado por características genéticas da planta em interação com o seu meio ambiente (Moraes Neto et al., 2000). Amo (1985), analisando essas mudanças no processo de regeneração e crescimento de mudas, concluiu que as diferenças de luz quanto à sua intensidade possuem, nas condições naturais, efeito mais significativo no crescimento das plantas do que a sua qualidade, principalmente no que se refere ao acúmulo de matéria seca. Diversas variáveis de crescimento têm sido utilizadas para avaliar o comportamento das mudas de espécies florestais em relação à luz, sendo a altura e o diâmetro de caule usados com maior freqüência. O maior diâmetro de caule é uma característica desejável em mudas porque garante maior sustentação da muda. A produção de matéria seca, a área foliar e as relações entre a biomassa das partes aérea e radicular são variáveis também utilizadas na avaliação do crescimento das mudas quanto à luz (Farias et al., 1997).

Os objetivos deste trabalho foram avaliar a capacidade germinativa das sementes de pitanga e o crescimento das mudas sob condições de sombreamento.

\section{MATERIAL E MÉTODOS}

As sementes foram coletadas diretamente das árvores quando os frutos se apresentavam completamente vermelhos. As sementes foram despolpadas e deixadas secar ao sol durante 48 horas. O experimento foi conduzido na Área de Pesquisa Experimental da UNIGRAN - Dourados-MS, no período de outubro de 1999 a junho de 2000.

A semeadura foi realizada em recipiente de polietileno de $10 \times 20 \mathrm{~cm}$, contendo como substrato terra adubada com esterco de curral curtido (10:1), sendo colocada 1 semente por recipiente, perfazendo um total de 300 sementes. A cada seis dias, durante três meses, foram realizadas contagens das sementes germinadas para cálculo da porcentagem germinativa e índice de velocidade de emergência segundo Popinigs (1985).

Aos três meses após a emergência, as mudas foram levadas para condição de sombrite $50 \%$ e $70 \%$ de luz e a pleno sol. O experimento foi conduzido em delineamento de blocos casualizados, com 4 repetições de 15 mudas por tratamento. Um mês após aclimatação das mudas, foram avaliadas a altura e o diâmetro de caule, com medições aos 4; 5; 6 e 7 meses de idade. Ao final do experimento, foram avaliados a área foliar $\left(\mathrm{dm}^{2}\right) \mathrm{com}$ auxílio de integrador de área foliar LI COR 3000 e o peso seco total das mudas (g), calculados a razão de peso foliar - RPF (g/ $\mathrm{g})$ e o peso específico de folhas PEF $\left(\mathrm{g} / \mathrm{dm}^{2}\right)$ segundo Benincasa (1988).

\section{RESULTADOS E DISCUSSÕES}

As sementes de pitanga apresentaram $65,7 \%$ de germinação, sendo essa porcentagem inferior àquela observada por Carvalho et al. (1998), que obtiveram germinação superior a $80 \%$. O índice de velocidade de emergência foi de 3,34 e as sementes iniciaram o processo de germinação aos 23 dias após a semeadura. Esses dados sugerem que as condições em que o teste de germinação foi conduzido, não foram plenamente satisfatórias para a germinação das sementes, embora uma germinação acima de $60 \%$ seja considerada boa em testes de germinação.

Durante os sete meses nos quais as mudas de pitangueira foram avaliadas, a altura e o diâmetro de caule mantiveram-se maiores naquelas crescendo a pleno sol (Figura 1). A altura e o peso seco foram maiores quando crescidas a pleno sol, não variando entre as sombrites (Tabela 1). O diâmetro de caule também foi maior a pleno sol, do que a $50 \%$ de sombreamento, todavia foi semelhante ao de $70 \%$ de sombreamento. A $50 \%$, as mudas apresentaram o menor diâmetro. Estes dados indicam que as mudas a pleno sol apresentaram maior crescimento, uma vez que o maior diâmetro de caule sugere maior particionamento de fotoassimilados da parte aérea.

A área foliar foi maior sob sombreamento, o que é normalmente observado nessa condição, uma vez que há necessidade de ampliar a superfície fotossintetizante para maximizar a absorção luminosa.

As mudas sob sombreamento, apresentaram menor peso seco e maior área foliar, quando comparadas com as mudas a pleno sol. Resultados semelhantes foram observados por Farias et al. (1997), estudando o desenvolvimento das mudas de cedrorana (Cedrelinga catanaeformis (Ducke) Ducke) sob pleno sol, 30; 50 e 70\% de luz. Esses resultados podem ser explicados baseado nos dados de peso específico de folha, que representa a espessura foliar. As folhas sob alta disponibilidade luminosa apresentam espessura foliar maior, como recurso de proteção aos pigmentos fotossintetizantes, o que pode ter contribuído para aumentar o peso seco total. Assim, analisando o peso específico da folha, observa-se que não houve diferenças significativas entre os sombreamentos, e que o valor foi inferior quando comparado com as mudas a pleno sol. Resultados semelhantes foram observados por Longstreth et al. (1981), trabalhando com Hydrocotyle bonaniensis Lam. e Farias et al. (1997), trabalhando com cedrorana .

As mudas a pleno sol apresentaram crescimentos em altura e diâmetro superiores desde o início do experimento, seguidas pelas mudas sob $70 \%$ de sombreamento (Figura 1). Provavelmente, os 30 dias em que as mudas permaneceram sob diferentes luminosidades para aclimatação, tenham sido suficientes para causar a diferença de crescimento em altura observada. Moraes Neto et al. (2000), estudando o desenvolvimento de mudas de espécies arbóreas, observaram diferenças significativas de comportamento em altura e diâmetro do caule entre as espécies, em relação aos diferentes níveis de luminosidade e idade, sendo que a sangra-d'água (Croton urucurana Baill ) apresentou maior altura em menor tempo comparado com o jenipapo (Genipa americana L. ). 


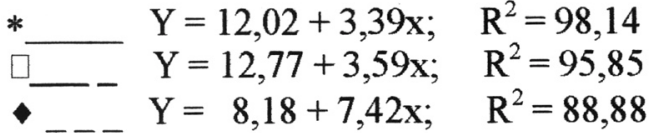

(a)

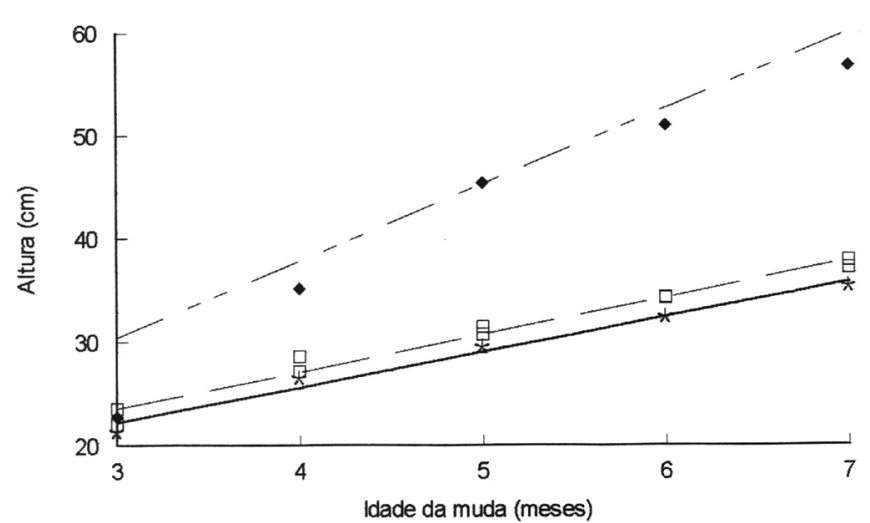

FIGURA 1 - Altura (a) e diâmetro (b) de mudas de pitanga sob 50\% (* Dourados-MS. 2000

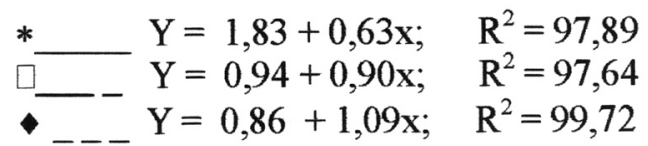

(b)

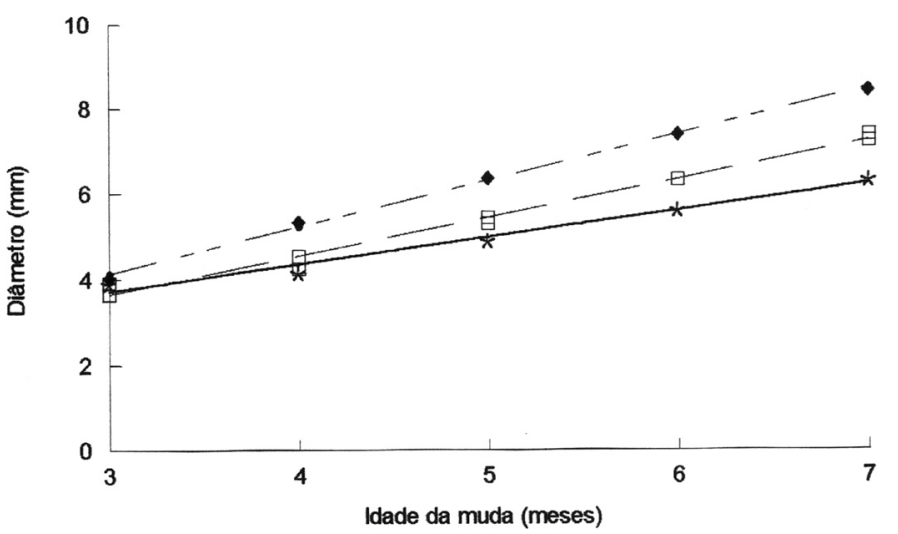
), $70 \%$ de luz $\left(\ldots \_\right)$e a pleno sol $\left(\bullet_{-}{ }_{-}\right)$. UNIGRAN,

TABELA 1 - Altura; diâmetro de caule; peso seco total; área foliar; razão do peso foliar-RPF; peso específico de folha -PEF de mudas de pitangueira com sete meses de idade sob diferentes condições de luz. UNIGRAN, Dourados-MS. 2000

\begin{tabular}{|c|c|c|c|c|c|c|}
\hline \multirow[t]{2}{*}{ A valiações } & \multicolumn{6}{|c|}{ D isponibilidade de Luz } \\
\hline & \multicolumn{2}{|l|}{$50 \%$} & \multicolumn{2}{|l|}{$70 \%$} & \multicolumn{2}{|l|}{ Pleno sol } \\
\hline Altura (cm) & 32,42 & $\mathrm{~b}$ & 34,29 & $\mathrm{~b}$ & 52,98 & $\mathrm{a}$ \\
\hline D iâm etro $(\mathrm{m} \mathrm{m})$ & 5,59 & $\mathrm{~b}$ & 6,31 & $a b$ & 7,35 & a \\
\hline Peso seco $(g)$ & 34,53 & $\mathrm{~b}$ & 34,63 & $\mathrm{~b}$ & 42,85 & a \\
\hline Área foliar $\left(\mathrm{dm}^{2}\right)$ & 191,92 & $\mathrm{a}$ & 189,02 & $\mathrm{a}$ & 143,57 & b \\
\hline RPF $(g / g)$ & 0,78 & $\mathrm{a}$ & 0,78 & $\mathrm{a}$ & 0,74 & a \\
\hline $\operatorname{PEF}\left(\mathrm{g} / \mathrm{dm}^{2}\right)$ & 0,14 & $\mathrm{~b}$ & 0,14 & $\mathrm{~b}$ & 0,22 & a \\
\hline
\end{tabular}

Médias seguidas de mesma letra minúscula na linha são estatisticamente iguais, pelo teste de Tukey, à 5\% de probabilidade.

\section{CONCLUSÃO}

Diante dos resultados, observa-se que a pitanga é uma espécie de fácil propagação por sementes, e suas mudas crescem melhor sob condição de luz plena.

\section{REFERÊNCIAS BIBLIOGRÁFICAS}

AMO, S.R. del Alguns aspectos de la influência de la luz sobre el crescimiento de estados juveniles de espécies primarias. In: GOMES-POMPA, A.; AMO, S.R. del. Investigaciones sobre la regeneracion de selvas altas em Vera Cruz. México: Instituto Nacional de investigações sobre recursos bióticos, Ed. Alhambra Mexicana \& A ., 1985. p.79-92.

BATALHA, M.A; ARAGAKI, S.; MANTOVANI, W. Florística do cerrado em Emas (Pirassununga, SP). Boletim Botânico da Universidade de São Paulo, v.16, p.49-64, 1997.

BENINCASA, M.M.P. Análise de crescimento de plantas (noções básicas), Jaboticabal: FCAV-UNESP, 1988. 41p.

CARVALHO, J.E.U.; NASCIMENTO, W.M.O.; MULLER, C.H. Características físicas e de germinação de sementes de espécies frutíferas nativas da Amazônia. Belém: EMBRAPA. Centro de Pesquisa Agroflorestal da Amazônia Oriental (Belém, PA). 1998. $18 \mathrm{p}$.

FARIAS, V.C.C.; COSTA, S.S.; BATALHA, L.F.P. Análise de crescimento de mudas de cedrorana (Cedrelinga catenaeformis (Ducke) Ducke) cultivadas em condições de viveiro. Revista Brasileira de Sementes, Brasília, v.19, n.2, p.193-200, 1997. 
KORBES, V.C. Plantas medicinais. 48. ed. Francisco Beltrão: Associação de Estudos, Orientação e assistência Rural, 1995. $188 \mathrm{p}$.

LONGSTRETH, D.J.; HARTSOCK, T.L.; NOBEL, P.S. Ligth effects on leaf development and photosynthetic capacity of Hydrocotyle bonariensis Lam. Photosynthesis Research, Dordrecht, v.2, p.92104, 1981.

LORENZI, H. Árvores brasileiras: manual de identificação e cultivo de plantas arbóreas nativas do Brasil. Nova Odessa, SP:Editora Plantarum, 1998. 352p.

MARTINS, S.V. Dinâmica de clareiras: aplicações na silvicultura e no manejo de florestas nativas. Folha Florestal: Informativo técnico do Departamento de Engenharia Florestal da Universidade Federal de Viçosa. n. 95, p. 15-17, 2000.

MORAIS NETO, S.P.; GONÇALVES, J.L. de M.; TAKAKI, M. ; CENCI, S.; GONÇALVES, J.C. Crescimento de mudas de algumas espécies arbóreas que ocorrem na mata atlântica em função do nível de luminosidade. Revista Árvore, Viçosa, v.24, n.1, p.35-45, 2000.

POPINIGS , F. Fisiologia de sementes .Brasília: Agriplan, 1985. 285p.

RIZZINI, C.T. Aspectos ecológicos da regeneração em algumas plantas de cerrado. In: SIMPÓSIO SOBRE O CERRADO 3., 1971, São Paulo. Anais... São Paulo: E. Blucher, EDUSP. 1971.

SILVA, M.L.; VALVERDE, S.R.; PASSOS, C.A.M. e COUTO, L. Viabilidade do reflorestamento do eucalipto consorciado com a cultura do feijoeiro: um estudo de caso. Revista Árvore, Viçosa, v.21,n.4, p.527-535, 1997.

SOUZA, A.L.; SILVA, E. Manejo para conservação da biodiversidade em fragmentos florestais. Informativo SIF, Viçosa, v.2,p.1-2, 1994. 